\title{
IDENTIFICAÇÃO E CARACTERIZAÇÃO DA REPELÊNCIA À ÁGUA EM ALGUNS SOLOS BRASILEIROS ${ }^{(1)}$
}

\author{
D. V. PÉRE $Z^{(2)}$, S. M. SIMÃO(3) \& A. SALATINO(4)
}

\begin{abstract}
RESUMO
Desde 1986, vem-se observando o fenômeno de repelência à água, em amostras de horizontes coletadas para levantamentos de solos realizados pelo Departamento de Solos da Universidade Federal Rural do Rio deJ aneiro (UFRRJ ) e pela EMBRAPA - Centro Nacional de Pesquisa de Solos. Com o objetivo de estudar as causas desse fenômeno, selecionaram-se sete amostras de solo que, inicialmente, foram submetidas à avaliação do grau de repelência à água pelos métodos da molaridade de gotas de etanol e tempo de penetração de gotas de água no laboratório de solos da UFRRJ. A fim de identificar os compostos orgânicos responsáveis pelo fenômeno da repelência, foram empregados dois métodos de extração, os quais foram eficientes na reti rada do caráter hidrofóbico das amostras. 0 primeiro teve por base o uso da partição isopropanol:água destilada, e o outro, desenvolvido pelos autores, empregou extrações simples com n-hexano, éter de petróleo e clorofórmio, além de partições n-hexano:água destilada e clorofórmio:água desti lada. As substâncias extraídas foram analisadas no Instituto de Biociências da Universidade de São Paulo (USP). Os resultados indicam que as substâncias isoladas têm sua origem na vegetação local, sendo os alcanos de alto peso molecular os responsáveis pelo caráter hidrofóbico das amostras de solo.
\end{abstract}

Termos de indexação: repelência à água, solos hidrofóbicos, extração.

\section{SUMMARY: IDENTIFICATION AND CHARACTERIZATION OF WATER REPELLENCY OF SOME BRAZILIAN SOILS}

Since 1986, theoccurrence of water repel lency has been observed in soil samples collected for soil surveys conducted by the Soil Department of Federal Rural University of Rio de J aneiro (UFRRJ ) and by the National Center for Soil Research of EMBRAPA. With the

(1) Recebido para publicação em julho de 1997 e aprovado em abril de 1998.

(2) Pesquisador da EMBRAPA - Centro Nacional de Pesquisa de Solos.CEP 22460-000 Rio de J aneiro (RJ ).

(3) Professora Adjunta III do Departamento de Ciências Ambientais, Universidade Federal Rural do Rio de J aneiro. CEP 23851-970 Seropédica (RJ).

(4) Professor Titular do Instituto de Biociências, Universidade de São Paulo. Caixa Postal 11461, CEP 05422-970 São Paulo (SP). 


\begin{abstract}
objective of studying the causes of this phenomenon, seven soils were selected and their water repel lence rating was determined by two methods: the molarity of ethanol droplets and water drops penetration time Two methods of extracti on wereused toisolateand identify the organic compounds responsible for the water repel lency. The first one was based in a partition with isopropanol:distilled water and the other one, devel oped by the authors, was based on single extractions with n-hexane, chloroform and ether and partitions with nhexane distilled water and chloroform:distilled water. Both methods madethewater-repel lent soils wettabl eafter theextraction. Theextracted substances wereanalyzed in the Institute of Biosciences of theU niversity of São Paulo. The results indicate that the isolated substances had their origin in thevegetation cover and that theal canes of high molecular weight were responsiblefor therepellency in these soils.
\end{abstract}

I ndex terms: water repellency, hydrophobic soi ls, extraction.

\section{NTRODUÇÃO}

Alguns sol os apresentam a propriedade de repelir a água, não se molhando facilmente pela água da chuva ou irrigação. Essefenômeno é comum em solos orgânicos drenados e expostos ao sol por muito tempo. Quando se tenta reidratá-los, observa-se, muitas vezes, o desprendimento de partes do material do solo na forma de placas, que flutuam pel os canais de drenagem.

As primeiras observações sobre a repelência à água em solos, chamados por al guns autores de solos hidrofóbicos (Giovannini et al., 1983), remontam a 1910, com Schreiner \& Shorey (Wallis \& Horne, 1992), em sol os da Califórnia (EUA). A importância dada a esse assunto pode ser demonstrada por um simpósio realizado especificamente sobre esse tema na Universidade da Califórnia (Riverside, EUA), em 1969, e pela revisão bibliográfica realizada por Wallis $\&$ Horne (1992).

O fenômeno da repelência à água em solos vem sendo observado em várias partes do mundo: Austrália (Bond, 1968), Nova Zelândia (Wallis et al., 1991), Estados Unidos (Wander, 1949), I tália (Giovannini et al., 1983) e J apão (Nakaya et al., 1977). No Brasil, foram encontradas menções da repelência do solo à água no Espírito Santo (E MBRAPA, 1978) em horizontes superficiais de um Latossolo Vermel ho-Amarelo distrófico textura argilosa (Município de Ecoporanga) e de um Podzólico Vermelho-Amarel o latossóli ico textura arenosa (Município de Mucurici). Em ambos os casos, os perfis estavam sob mata secundária. Também há menções sobre a dificuldade de reidratação de um Glei Tiomórfico, localizado no Estado do Rio de J aneiro (Município de Cabo Frio), sob vegetação de campo hidrófilo (E MBRAPA, 1979a).

A repelência do solo à água seria causada pelo recobrimento das partículas do sol o por substâncias orgânicas hidrofóbicas, embora isto não signifique que o grau de repelência esteja relacionado com o teor de matéria orgânica, uma vez queWallis et al.
(1993) citam uma série de trabal hos em que o maior grau de repelência à água está em sol os com menores teores de carbono orgânico, levando à conclusão de que o caráter hidrofóbico está relacionado com a qualidade, e não com a quantidade dessas substâncias orgânicas.

Várias podem ser as origens das substâncias orgânicas responsáveis pela repelência. A vegetação local, em função da sua composição química, pode contribuir com compostos orgâni cos hidrofóbicos, via deposição ou por decomposição, que, recobrindo as partículas do solo, criam o caráter de repelência à água (Roberts \& Carbon, 1972; McGhie \& Posner, 1980). Nesse sentido, os microrganismos também exercem um papel importante(Bond, 1969; Adhikari \& Chakrabarti, 1976), já que são os principais decompositores da matéria orgânica do solo. Além disso, alguns fungos possuem micélios, cuja superfície é recoberta por substâncias hidrofóbicas (Wallis \& Horne, 1992). O aquecimento do solo, através de incêndios, é outro fator importante na geração do caráter de repelência à água, principalmente por meio do mecanismo de volatilização, migração no solo e condensação de substâncias orgânicas hidrofóbicas (DeBano et al., 1970; School, 1975). Alguns autores também reconhecem a influência de val ores de $\mathrm{pH}$ el evados, particularmente acima de 6,5, na diminuição da repelência à água deal guns sol os (Roberts \& Carbon, 1972; Adhikari \& Chakrabarti, 1976). Em tais valores de $\mathrm{pH}$ solubilizar-se-iam os ácidos húmicos, um dos prováveis responsáveis pela repelência à água (Adhikari \& Chakrabarti, 1976).

N ormalmente, a existência do caráter hidrofóbico em determinado solo traz aspectos negativos com respeito ao seu uso e manejo. Wander (1949) e Bond (1968) indicam que o efeito primário da repelência é a redução da taxa de infiltração da água no sol o. Com isso, a quantidade de água disponível é diminuída, afetando a germinação de sementes e o crescimento vegetal (Bond, 1968; Bond, 1972). Além disso, pela menor infiltração, também pode ocorrer o aumento do escorrimento superficial da água, principalmente 
em áreas ded ivosas, o que aumenta a erosão (McGhie \& Posner, 1980; Giovannini et al., 1983). Wallis \& Horne (1992) também citam outros efeitos secundários, tais como o desenvolvimento de fluxos preferenciais de água no solo e o aumento da estabilidade de agregados.

O objetivo deste trabal ho foi caracterizar o grau de repelência à água e as substâncias responsáveis por esse fenômeno, em amostras de solo onde já se havia verificado visual mente o caráter hidrofóbico.

\section{MATERIAL E MÉTODOS}

Foram estudadas sete amostras oriundas de horizontes A ou B de solos minerais coletados em levantamentos de solos realizados em diversas regiões brasileiras (Quadro 1). Os teores de carbono orgânico, areia, argila e pH em água foram determinados segundo EMBRAPA (1979b).

Dois métodos de estimativa da repelência do solo à água, descritos na íntegra em King (1981), foram utilizados para as sete amostras de solo, antes que estas fossem submetidas aos processos de extração dos componentes hidrofóbicos, de modo a caracterizar o grau de repelência. Ambos os métodos seutilizam de material de sol o seco ao ar que passou pela peneira de $2 \mathrm{~mm}$. O primeiro método, molaridade de gotas de etanol ("molarity of ethanol droplets" ou MED), consiste na aplicação de duas gotas $(40 \mu \mathrm{L})$ de solução aquosa de etanol, de concentração conhecida, e na medição do tempo necessário para a absorção das gotas pelo solo.Tal procedimento é para concentrações que variam de 0 a $5 \mathrm{~mol} \mathrm{~L}-1$, com intervalos de $0,2 \mathrm{~mol} \mathrm{L-1}$. A repelência será representada pela molaridade da solução etanólica a partir da qual as gotas penetram na superfície da amostra em menos de dez segundos. O outro método, tempo de penetração de gotas de água ("water drops penetration time" ou WD), baseiase no tempo gasto para que duas gotas de água
( $40 \mu \mathrm{L}$ ) penetrem na amostra de terra. Levando em consideração os valores obti dos, princi pal mente, por esses dois métodos, King (1981) define o grau de repelência à água (Quadro 2 ).

Foram testados dois métodos para a extração dos componentes hidrofóbicos das amostras de solo. O primeiro método de extração, desenvolvido por Ma'Shum et al. (1988), consiste da extração, por agitação e filtragem, de $200 \mathrm{~g}$ de terra fina seca ao ar com $200 \mathrm{~mL}$ de soluçãoisopropanol :água destilada (7:3, vol ume:volume). Foi feita uma extração diária, durante quatro dias, com agitação média de cinco horas em agitador horizontal. Esse método simples de partição foi testado para todas as sete amostras, embora sótenham sidoanalisados, cromatograficamente, os extratos das amostras 1, 2, 4, 5 e 6a. As amostras 3 e $6 b$ produziram extratos em quantidade insuficiente para posterior análise cromatográfica. A pós a extração, todas as amostras desolo voltaram a passar pel os métodos MED eWD, para constatar o fim do carater hidrofóbico das amostras. Essemétodo érápido e fácil, mas é baseado em uma partição com somente um solvente orgânico. Assim, os diversos componentes orgânicos presentes em uma amostra são extraídos em um único extrato, o que pode vir a dificultar a identificação da classe ou classes de substâncias a que pertenceriam as moléculas responsáveis pela hidrofobicidade das amostras.

Por essa razão, criou-se um segundo método de extração, visando obter vários extratos advindos do uso de solventes orgânicos com polaridade diferenciada. Esse segundo método (Figura 1) foi aplicado primeiramente à amostra 1 . Consistiu de dois processos de extração: por aparato de Sohxlet e por partição com água. No aparato de Sohxlet, foi introduzi da uma nova amostra de $120 \mathrm{~g}$ de terra fina seca ao ar da amostra 1 e $500 \mathrm{~mL}$ de solvente orgânico. Esse sistema ficou em funcionamento por quatro horas, após o que a amostra de solo era deixada secar ao ar. Depois de seca, a amostra era submetida aos testes MED e WD. Mantida a hidrofobicidade, a amostra retornava ao Sohxlet,

Quadro 1. Identificação das amostras de solos brasi leiros coletadas para o estudo do grau de repelência à água e da caracterização das substâncias orgânicas responsáveis pelo fenômeno

\begin{tabular}{cllll}
\hline Amostra & Localização (Município/E stado) & Classe de solo & Horizonte & Vegetação \\
\hline 1 & Pinheiros (MA) & Areia Quartzosa & A & Palmeira \\
2 & Casemiro de Abreu (RJ) & Areia Quartzosa & A & Campo hidrófilo \\
3 & Caxias (MA) & Aluvial & A & Palmeira \\
4 & São Félix do Araguaia (PA) & Podzólico Vermelho-Amarelo & A & A \\
5 & Sepetiba (RJ) & Podzol Hidromórfico & A & Gramínea \\
$6 a$ & Rio das Ostras (RJ) & Podzol Hidromórfico & Bh & Gramínea \\
$6 b$ & Rio das Ostras (RJ) & Podzol Hidromórfico & B & \\
\hline
\end{tabular}


Quadro 2. Caracterização do grau de repelência à agua através dos métodos das gotas de etanol (MED) e do tempo de penetração de gotas de água (WD), com base em King (1981)

\begin{tabular}{clcc}
\hline $\begin{array}{c}\text { Grau de } \\
\text { repelência }\end{array}$ & Severidade & MED & WD \\
\hline & mol L-1 & $\mathrm{s}$ \\
1 & Não-significante & - & $<1$ \\
2 & Muito baixa & - & $1-7$ \\
$3-5$ & Baixa & $0,0-1,0$ & $8-53$ \\
$6-8$ & Moderada & $1,2-2,2$ & $85-260$ \\
$9-10$ & Severa & $2,4-3,0$ & $>260$ \\
$11-12$ & Muito Severa & $>3,2$ & $>260$ \\
\hline
\end{tabular}

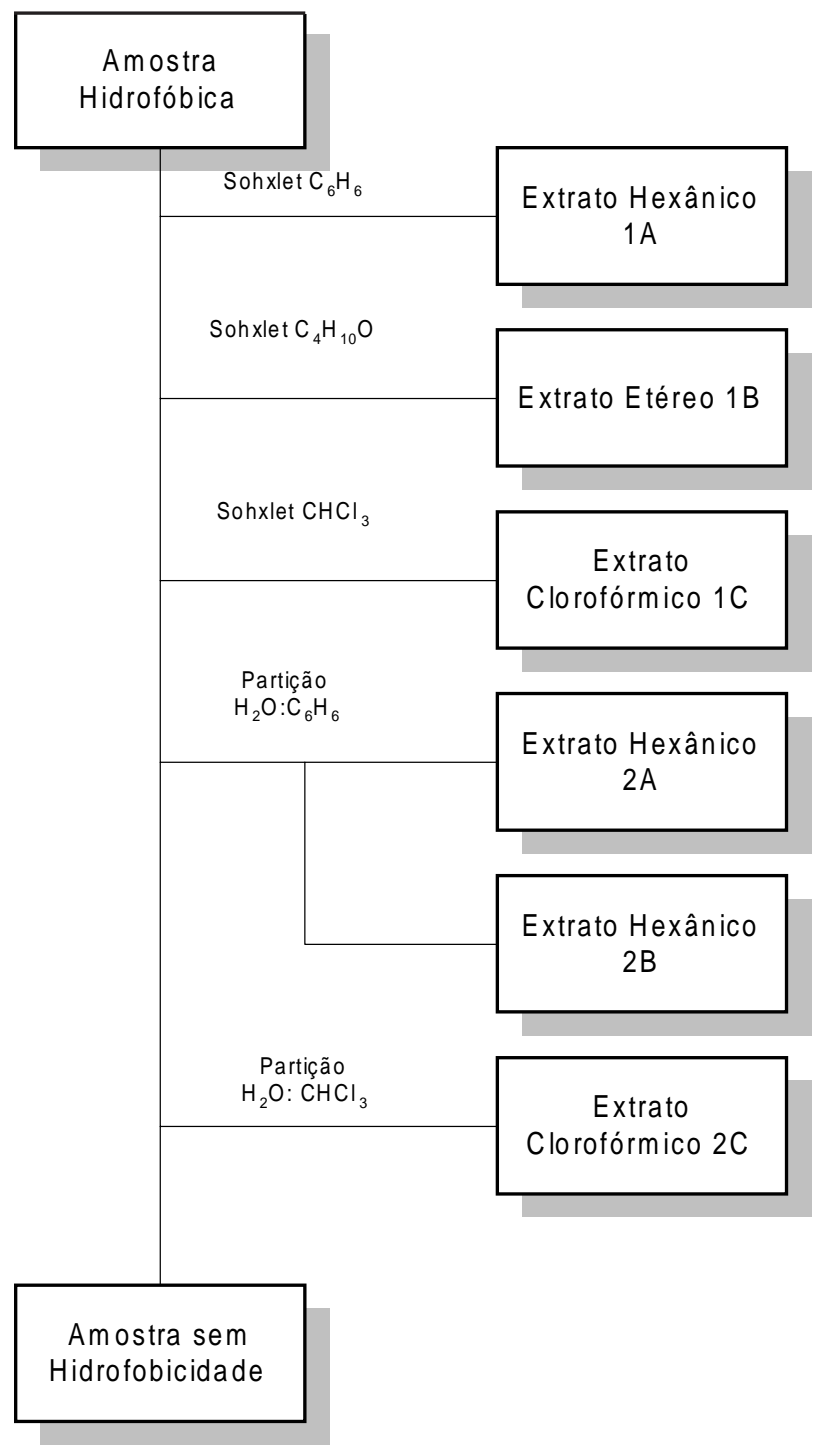

Figura 1. Etapas do método de extração, proposto pelos autores, dos componentes hidrofóbicos de amostras de solo que apresentem o caráter de repelência à água. passando a ser extraída com novo solvente de polaridade maior. Foram utilizados três solventes nesse processo: n-hexano, éter de petróleo e clor ofórmio, sucessivamente.

Uma vez que esse processo se mostrou ineficaz para eliminar a característica hidrofóbica, adotouse o processo de partição de água com solvente orgânico, com a mesma amostra de solo. A amostra foi introduzida em um funil de decantação com $100 \mathrm{~mL}$ de solvente e mesma quantidade de água destilada. Após agitação manual por $5 \mathrm{~m}$, o sistema foi deixado em repouso por $24 \mathrm{~h}$, depois do que a fase orgânica era separada do sistema e outros $100 \mathrm{~mL}$ de solvente eram adicionados. Esse procedimento foi repetido por 5 dias, após o que a amostra desol o seca ao ar era novamente submetida aos testes MED e WD. Foram usados, consecutivamente, como solventes orgânicos, o n-hexano e o clor ofórmio (Figura 1). A pós a partição água/cl orofórmio, verificou-se o desaparecimento do caráter hidrofóbico da amostra de solo. Por mostrarse muito demorado, o segundo método foi utilizado apenas na amostra 1.

Os extratos orgâni cos, obtidos pel os dois métodos, de Ma'Shum et al. (1988) e por Sohxlet/partição, foram concentrados por evaporação em aparato Rotavapor com vácuo de $12 \mathrm{~cm} \mathrm{Hg}$ e temperatura média do banho-maria de $50^{\circ} \mathrm{C}$. Todos os extratos orgânicos obtidos pelos dois métodos foram analisados por cromatografia de camada fina com placas de vidro recobertas com sílica gel G Typ 60, impregnadas com fluoresceína sódica, segundo método de Salatino \& Silva (1988). As placas foram eluídas com ciclo-hexano:clorofórmio (7:3, volume:volume), contendo, como padrões de referência, o n-tetracosano, o hexadecanoato de triacontila eo áci do esteárico. Por esse método, foram separadas, para alguns extratos, frações de hidrocarbonetos, ésteres e ácidos graxos, que foram reunidas e analisadas num cromatógrafo a gás CG-37. Utilizou-se um detector deionização dechama e integrador-processador CG-300, coluna capilar de sílica fundida (10 m), fase estacionária OV 101, gás de arraste hidrogênio, temperatura do injetor e detector $280^{\circ} \mathrm{C}$ e programação de temperaturas da coluna $120-280^{\circ} \mathrm{C}$ a $4^{\circ} \mathrm{C} / \mathrm{m}$. No caso dos ácidos graxos, foi feita metilação com diazometano.

\section{RESULTADOS E DISCUSSÃO}

Os resultados obtidos pel os testes MED eWD nas sete amostras testadas, bem como outras propriedades químicas e físicas analisadas, encontram-se no quadro 3. O grau de repelência, determinado com base nos dois testes, variou de muito baixo a moderado, nas sete amostras de solo (Quadro 3). 
Quadro 3. Repelência à água determinada através do método das gotas de etanol (MED) e do método do tempo de penetração de gotas de água (WD) e algumas propriedades físicas e químicas das sete amostras de solos estudadas

\begin{tabular}{|c|c|c|c|c|c|c|c|}
\hline Amostra & MED & WD & Grau de repelência(1) & Argila & Areia & Carbono orgânico & $\mathrm{pH}\left(\mathrm{H}_{2} \mathrm{O}\right)$ \\
\hline & $\mathrm{mol} \mathrm{L}^{-1}$ & $\mathrm{~s}$ & & 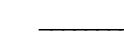 & - $\mathrm{g} \mathrm{k}$ & - & \\
\hline 1 & 0,2 & 10 & Baixo (3) & 60 & 850 & 118 & 4,7 \\
\hline 2 & 1,8 & 142 & Moderado (7) & 40 & 970 & 269 & 7,1 \\
\hline 3 & 0,6 & 23 & Baixo (4) & 80 & 870 & 118 & 6,0 \\
\hline 4 & 0,2 & 15 & Baixo (3) & 80 & 810 & 258 & 4,5 \\
\hline 5 & 0,0 & 6 & Muito Baixo (2) & 60 & 900 & 113 & 5,4 \\
\hline $6 a$ & 0,0 & 3 & Muito Baixo (2) & 30 & 960 & 58 & 4,5 \\
\hline $6 b$ & 1,4 & $>260$ & Moderado (6) & 40 & 920 & 176 & 4,3 \\
\hline
\end{tabular}

(1) Com base no quadro 2.

Todas as amostras apresentaram textura arenosa (Quadro 3), o que condiz com a maior parte dos estudos já realizados sobre esse assunto, segundo Wall is \& Horne (1992). Os mesmos autores citaram, ainda, que os casos mais extremos de repelência à agua foram constatados em solos arenosos, em decorrência da maior facilidade de recobrimento da areia por substâncias hidrofóbicas, dada a baixa superfície específica desses solos. Vale observar, contudo, que solos mais argilosos também podem apresentar o caráter hidrofóbico.

E mbora a quantidade de amostras fosse pequena, pode-se notar quea repelência à água foi mais severa nos solos que apresentaram maiores teores de carbono orgânico (Quadro 3), exceto para a amostra 4. Esta exceção, como já afirmaram Wallis et al. (1993), é devida à natureza, e não à quantidade de matéria orgânica que deve determinar a repelência.

$\mathrm{O}$ pH em água não apresenta aparentemente nenhuma relação com os valores de repelência obtidos (Quadro 3), o que pode ser demonstrado pel o baixo coeficiente de correlação ( $r=0,508$ n.s.).

As amostras $6 a$ e $6 \mathrm{~b}$ representam, respectivamente, os horizontes A e Bh do mesmo perfil de solo, caracterizado como um Podzol Hidromórfico (Quadro 1). A análise do quadro 3 revela que, enquanto o grau de repelência de $6 a$ é "Muito Baixo", o de 6b é "Moderado," e a amostra 5 representa também um horizonte $\mathrm{A}$ de um Podzol Hidromórfico, apresentando grau de repelência "Muito Baixo". Apesar do pequeno número de amostras, esses dados parecem sugerir que, nos Podzóis, os componentes hidrofóbicos migrariam dentro do perfil do solo como parte da matéria orgânica iluviada, como já foi observado por Qualls \& Haine (1991), concentrando-se no horizonte Bh. Tal hipótese justificaria o maior grau de repelência da amostra $6 \mathrm{~b}$ (horizonte $\mathrm{B}$ ) em relação à de $6 \mathrm{a}$ (horizonte $A$ ) e a semel hança de grau de repelência das amostras 5 (horizonte A) e 6a.
O método de extração de Ma'Shum et al. (1988) foi bastante eficiente na retirada do material orgânico responsável pela repelência à água, já que nenhuma das sete amostras apresentou esse caráter ao final da extração. As amostras 3 e 6 b não produziram extratos em quantidade suficiente para análise. As substâncias orgânicas obtidas das outras amostras por esse método de extração foram analisadas por cromatografia de camada fina, revelando a presença de n-al canos, ésteres e álcoois graxos primários, todos alifáticos (Quadro 4). Essas dasses desubstâncias são comuns em ceras vegetais. As frações de hidrocarbonetos, ésteres e álcoois graxos primários presentes nas amostras não foram obtidas com altos rendimentos. As quantidades de ésteres eálcoois disponíveis não possi bilitaram a sua análise por cromatografia a gás. Os hidrocarbonetos dos extratos das amostras 1, 4 e 5 foram analisados por cromatografia a gás. O resultado obtido para a amostra 1 (Quadro 5) caracteriza a predominância dealcanos de 25 átomos de carbono. As amostras $4 \mathrm{e}$ 5 , ao contrário, caracterizam-se por uma mistura de n-alcanos de 24 a 38 átomos de carbono com pouca

Quadro 4. Substâncias orgânicas detectadas, por cromatografia de camada fina, nos extratos obtidos pela aplicação do método de partição água:i sopropanol (Ma'Shun et al., 1988) às amostras 1, 2, 4, 5 e 6 a

\begin{tabular}{cccc}
\hline Amostra & Alcanos & É steres & Álcoois primários \\
\hline 1 & $\mathrm{X}$ & $\mathrm{X}$ & $\mathrm{X}$ \\
2 & & $\mathrm{X}$ & $\mathrm{X}$ \\
4 & $\mathrm{X}$ & $\mathrm{X}$ & \\
5 & $\mathrm{X}$ & & $\mathrm{X}$ \\
$6 \mathrm{a}$ & & $\mathrm{X}$ & $\mathrm{X}$ \\
\hline
\end{tabular}


representação de al canos ramificados. Os extratos hexânicos, etéreos e d orofórmicos obtidos da amostra 1 (Figura 1; extração por Sohxlet) também foram analisados por cromatografia de camada fina, revelando-se predominância de hidrocarbonetos e pequena quantidade de ésteres, ambos al ifáticos. As amostras de hidrocarbonetos foram reunidas, e a mistura anal isada por cromatografia em fase gasosa. O resultado obtido (Quadro 6; Figura 2) caracteriza uma mistura complexa de n-alcanos de 18 a 37 átomos de carbono, além de alcanos ramificados (Figura 2), representados pel os picos intermediários àqueles dos n-al canos no cromatograma. A pesar da obtenção desse material orgânico pela extração por Sohxlet, a amostra 1 não perdeu seu caráter hidrofóbico após esse processo.

As extrações por partição do segundo método (Figura 1), ao contrário, foram eficientes na retirada do material orgânico responsável pela repelência à água observada na amostra 1 . Os extratos provenientes da partição (Figura 1) foram submetidos, separadamente, aos tratamentos cromatográficos (gás e camada fina). O resultado foi o isolamento de n-al canos al ifáticos, ramificados ou não, de 16 a 35 átomos de carbono (Quadro 7; F iguras 3, 4 e 5) e ácidos graxos alifáticos livres de 14 a 34 átomos de carbono, ramificados ou não (Quadro 8; Figuras 6, 7 e 8). Tais resultados, obtidos pelo

Quadro 5. Hidrocarbonetos (alcanos) detectados, por cromatografia a gás, nos extratos, obtidos pela aplicação do método de partição água:isopropanol (Ma'Shun et al., 1988) às amostras 1, 4 e 5

\begin{tabular}{lccc}
\hline $\begin{array}{c}\text { Número de átomos } \\
\text { de carbono do alcano }\end{array}$ & $\mathbf{1}$ & $\mathbf{4}$ & $\mathbf{5}$ \\
\hline \multicolumn{4}{c}{ Composição percentual molar } \\
C24 & 2,0 & - & 2,0 \\
C25 & 92,0 & 7,0 & 6,0 \\
C26 & - & 11,0 & 9,0 \\
C27 & 2,0 & 16,0 & 12,0 \\
C28 & 1,0 & 16,0 & 12,0 \\
C29 & 1,0 & 14,0 & 13,0 \\
C30 & - & 10,0 & 10,0 \\
R-C31 & - & - & 1,0 \\
C31 & 3,0 & 9,0 & 9,0 \\
R-C32 & - & - & 1,0 \\
C32 & - & 6,0 & 7,0 \\
C33 & - & 4,0 & 5,0 \\
R-C34 & - & - & 1,0 \\
C34 & - & 3,0 & 4,0 \\
C35 & - & 2,0 & 4,0 \\
C36 & - & - & 2,0 \\
C37 & - & - & 1,0 \\
C38 & - & - & 1,0 \\
\hline
\end{tabular}

Cn: Alcano não ramificado; R-Cn: Alcano ramificado.
Quadro 6. Hidrocarbonetos (alcanos) detectados, por cromatografia a gás, na mistura dos extratos hexânicos (1A), etéreos (1B) e clorofórmicos (1C), obtidos pela aplicação do método proposto pelos autores à amostra 1

\begin{tabular}{ccc}
\hline $\begin{array}{c}\text { Número de átomos } \\
\text { de carbono do } \\
\text { alcano }\end{array}$ & $\begin{array}{c}\text { Homólogo } \\
\text { normal } \\
\text { ramificado }\end{array}$ & Homólogo \\
\hline & & $\%$ \\
C18 & 1,5 & 0,5 \\
C19 & 1,5 & 0,4 \\
C20 & 3,3 & 1,7 \\
C21 & 2,8 & 4,2 \\
C22 & 3,6 & 4,1 \\
C23 & 3,6 & 7,6 \\
C24 & 3,3 & 3,0 \\
C25 & 6,4 & 8,0 \\
C26 & 2,9 & 1,7 \\
C27 & 3,9 & 3,1 \\
C28 & 2,4 & 0,6 \\
C29 & 6,7 & - \\
C30 & 2,3 & - \\
C31 & 9,3 & - \\
C32 & 1,7 & - \\
C33 & 4,2 & 0,8 \\
C34 & 0,6 & 0,7 \\
C35 & 1,2 & 0,4 \\
C36 & 0,2 & 0,6 \\
C37 & 0,6 & 0,6 \\
Total & 62,0 & 38,0 \\
\hline
\end{tabular}

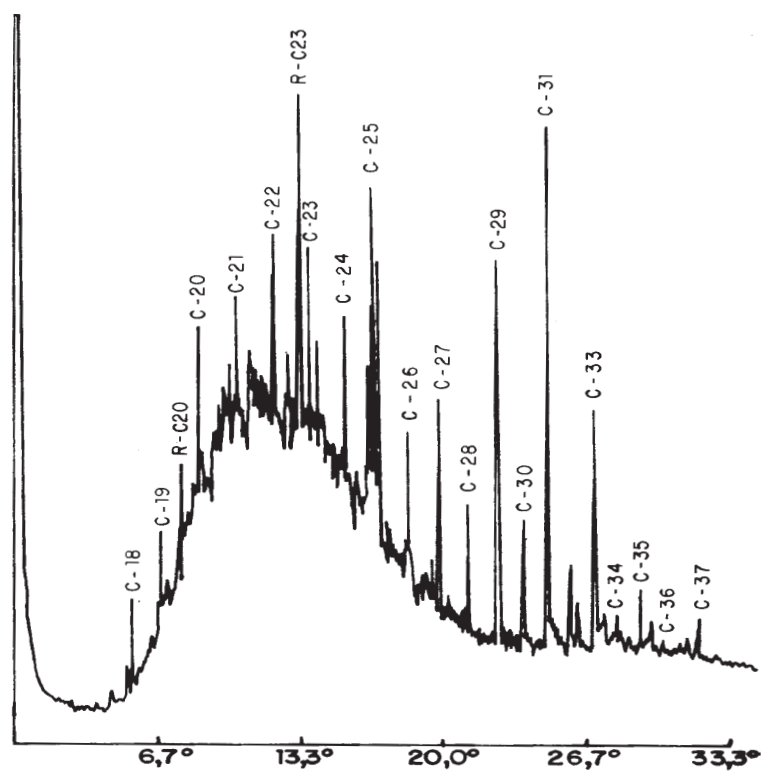

Figura 2. Cromatograma que identifica os hidrocarbonetos existentes na mistura dos extratos hexânicos (1A), etéreos (1B) e clorofórmicos (1C), obtidos pela aplicação do método proposto pelos autores à amostra 1. $C-\mathbf{X}=$ alcanos lineares; $\mathbf{R}-\mathrm{C}-\mathrm{X}=$ alcanos ramificados. 
segundo método de extração para a amostra 1, parecem indicar que as substâncias isoladas são de origem vegetal e de plantas superiores, uma vez que os al canos principais são C25, C27, C29, C31 e C33, que normalmente figuram como homól ogos das ceras do grupo vegetal que predomina na área de coleta da amostra 1, ou seja, palmeiras. A composição dos extratos é complexa, provavel mente pela ação microbiol ógica de decomposi ção das ceras das fol has, não só das palmeiras, como de outras plantas que ocorrem também na área, como, por exemplo, gramíneas. O método de Ma'Shum et al. (1988) extraiu n-alcanos, ésteres eálcoois graxos primários, enquanto o segundo método também extraiu n-alcanos, mas acompanhados por ácidos graxos (Quadros 5, 6, 7 e 8).

Devem-se ressaltar alguns fatos ocorridos durante os processos de partição por água com n-hexano e clorofórmio do segundo método. Quando da adição de n-hexano à amostra 1 com água e posterior agitação para facilitar o contato dos solventes com o solo, houve formação de uma interfase espumosa que inviabilizava a separação das duas fases. Para a eliminação de tal interfase, decidiu-se pela adição de $\mathrm{NaCl}$, em quantidades suficientes para eliminar a espuma, pelo aumento da tensão superficial. Durante a seqüência da extração, observou-se na partição água/clorofórmio que o solo estava em suspensão dentro da fase clorofórmica, impedindo a separação do solvente. Provavelmente, o sal utilizado para eliminar a espuma da partição água/n-hexano elevou a
Quadro 7. Hidrocarbonetos (alcanos) detectados, por cromatografia a gás, nos extratos da partição água:hexano (2A e 2B) e água:clor ofórmio (2C), obtidos pela aplicação do método proposto pelos autores à amostra 1

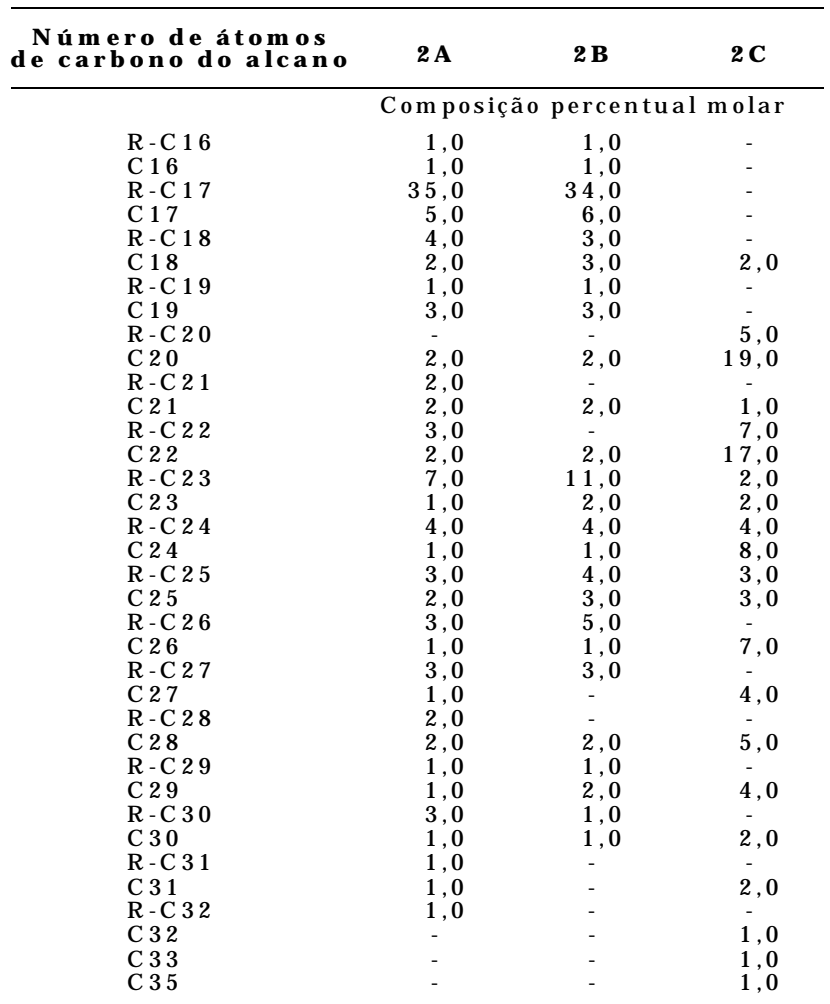

Cn: Alcano não ramificado; R-Cn: Alcano ramificado.

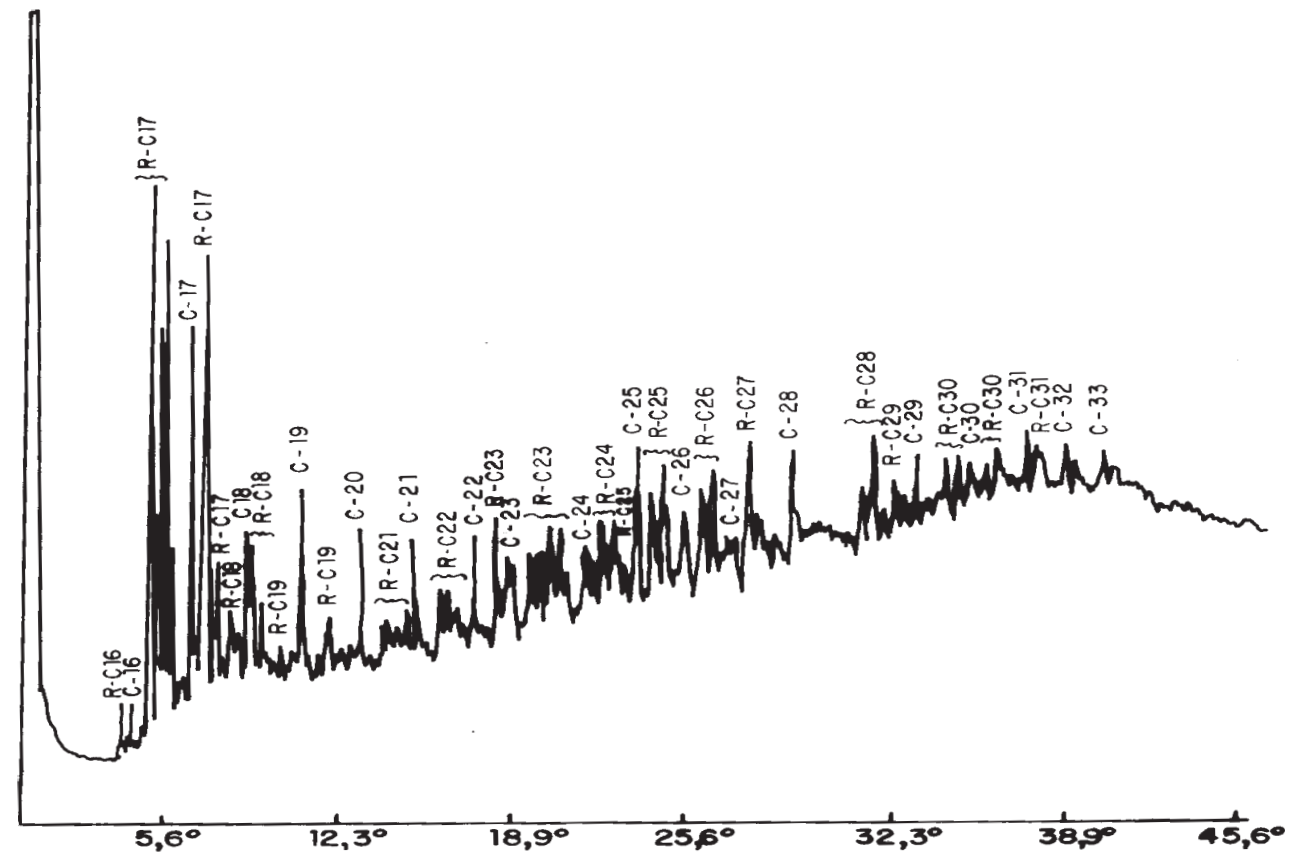

Figura 3. Cromatograma que identifica os hidrocarbonetos existentes no primeiro extrato da partição água:hexano (2A), obtido pela aplicação do método proposto pelos autores à amostra $1 . R-x=a l c a n o s$ ramificados. 


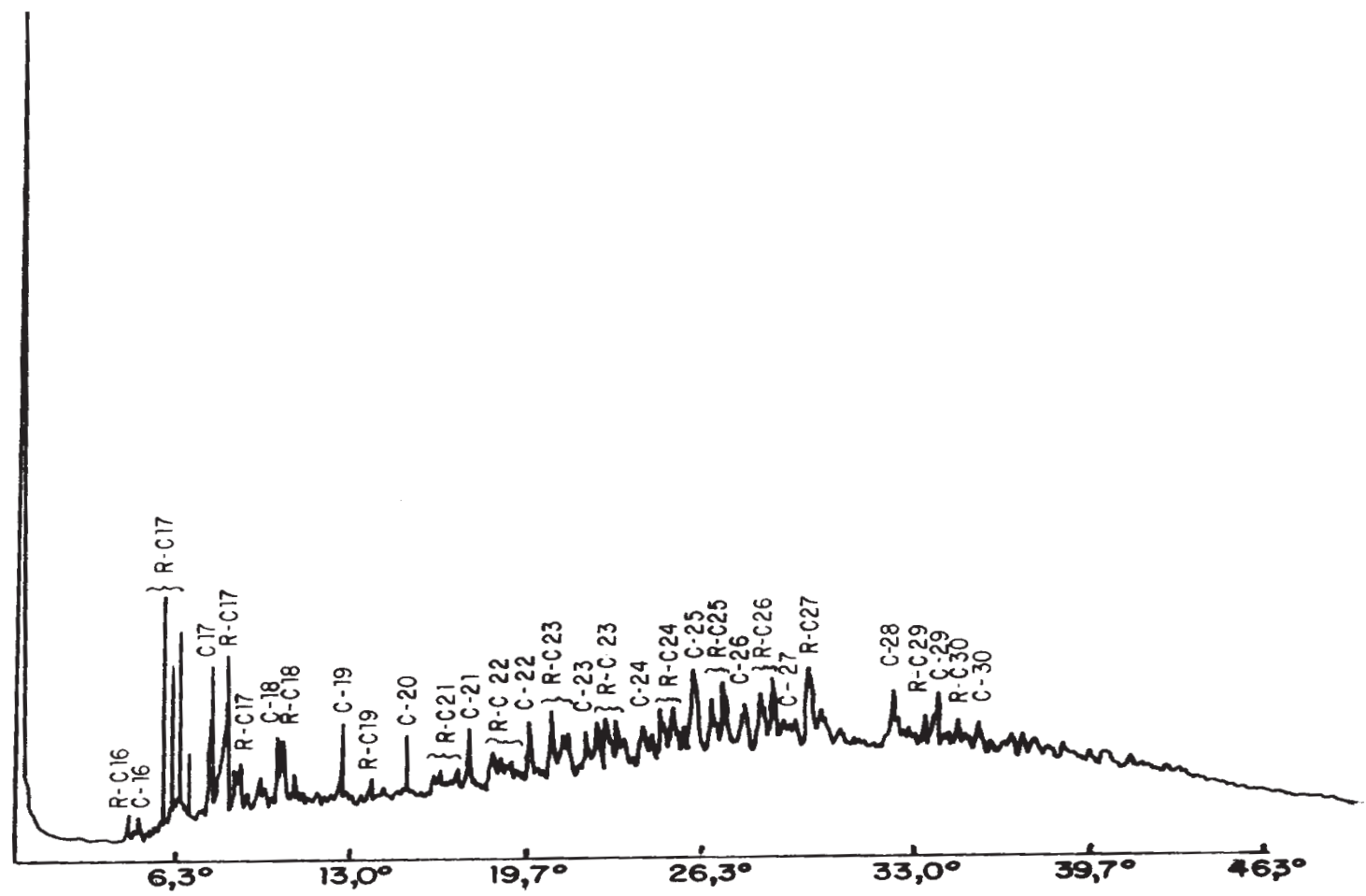

Figura 4. Cromatograma que identifica os hidrocarbonetos existentes no segundo extrato da partição água:hexano (2B), obtido pela aplicação do método proposto pelos autores à amostra $1 . \mathbf{R}-\mathbf{x}=$ alcanos ramificados.

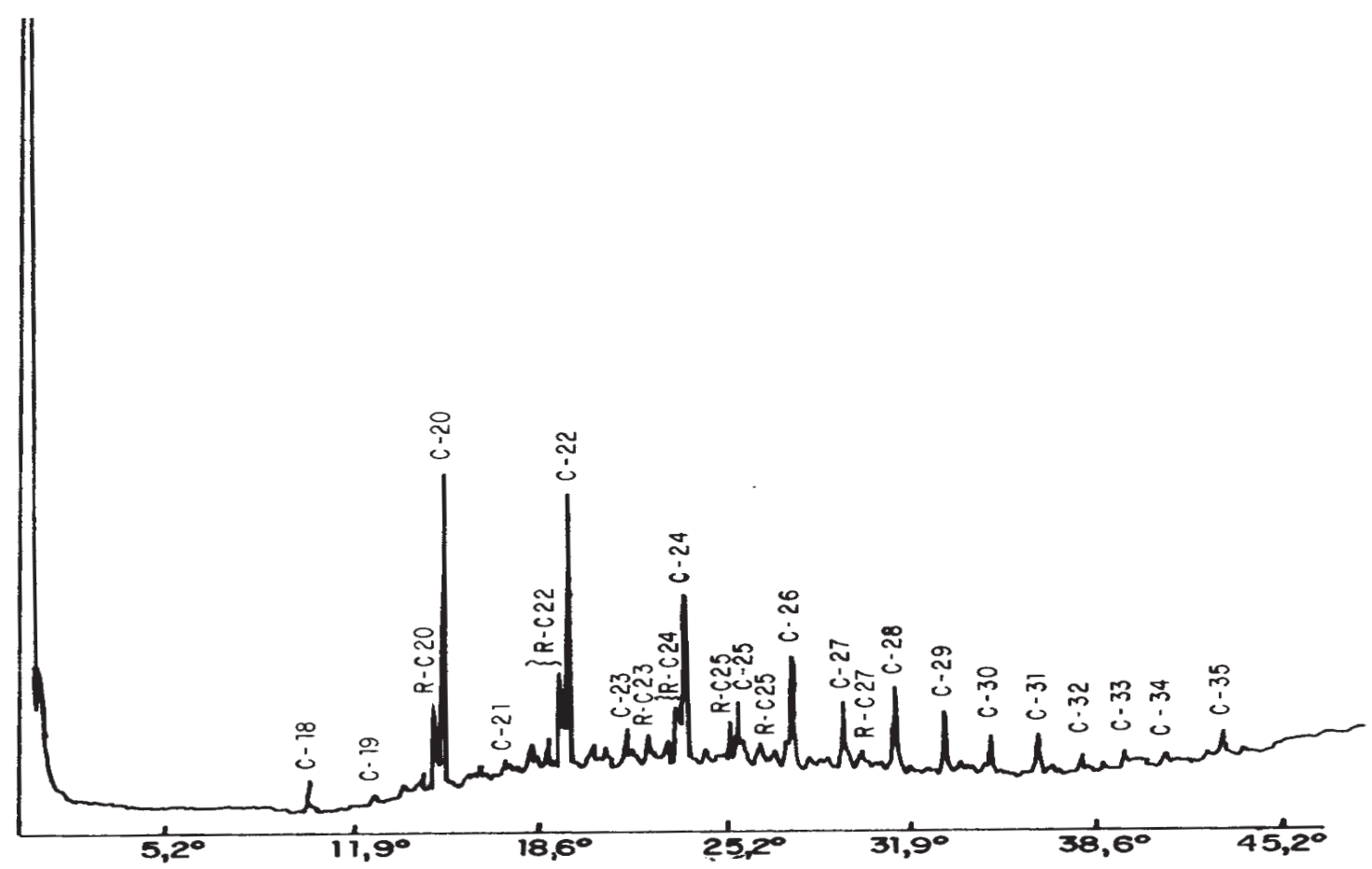

Figura 5. Cromatograma que identifica os hidrocarbonetos existentes no extrato da partição água:clorofórmio (2C), obtido pela aplicação do método proposto pelos autores à amostra 1. $\mathrm{C}-\mathbf{x}=$ alcanos lineares; $\mathbf{R}-\mathbf{x}=$ alcanos ramificados. 
Quadro 8. Ácidos graxos detectados, por cromatografia a gás, nos extratos da partição água:hexano (2A e 2B ) eágua:clorofórmio (2C), obtidos pela aplicação do método proposto pelos autores à amostra 1

\begin{tabular}{|c|c|c|c|}
\hline $\begin{array}{l}\text { Número de átomos de } \\
\text { carbono do alcano }\end{array}$ & 2A & 2B & 2C \\
\hline & \multicolumn{3}{|c|}{ Composição percentual molar } \\
\hline 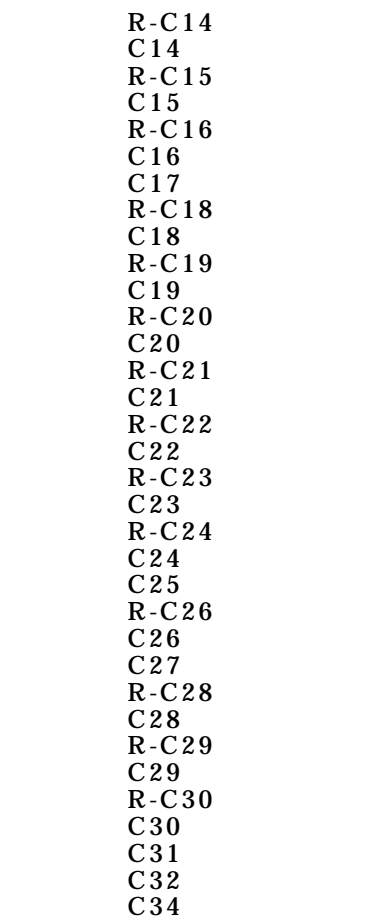 & $\begin{array}{r}1,0 \\
1,0 \\
1,0 \\
9,0 \\
9,0 \\
3,0 \\
1,0 \\
2,0 \\
3,0 \\
2,0 \\
1,0 \\
2,0 \\
10,0 \\
2,0 \\
2,0 \\
6,0 \\
8,0 \\
- \\
1,0 \\
4,0 \\
1,0 \\
13,0 \\
2,0 \\
2,0 \\
2,0 \\
1,0 \\
2,0 \\
2,0 \\
2,0 \\
1,0 \\
1,0 \\
1,0 \\
1,0 \\
1,0\end{array}$ & $\begin{array}{c}- \\
- \\
- \\
- \\
- \\
- \\
- \\
- \\
- \\
- \\
- \\
- \\
- \\
- \\
- \\
- \\
100,0 \\
- \\
- \\
- \\
- \\
- \\
- \\
- \\
- \\
- \\
- \\
- \\
- \\
- \\
- \\
- \\
-\end{array}$ & $\begin{array}{r}- \\
1,0 \\
- \\
3,0 \\
- \\
2,0 \\
- \\
34,0 \\
2,0 \\
1,0 \\
2,0 \\
2,0 \\
10,0 \\
- \\
2,0 \\
- \\
147,0 \\
2,0 \\
2,0 \\
4,0 \\
2,0 \\
2,0 \\
1,0 \\
1,0 \\
2,0 \\
- \\
2,0 \\
- \\
4,0 \\
-\overline{2}, 0 \\
2,0 \\
1,0 \\
-1\end{array}$ \\
\hline
\end{tabular}

Cn: Alcano não ramificado; R-Cn: Alcano ramificado.

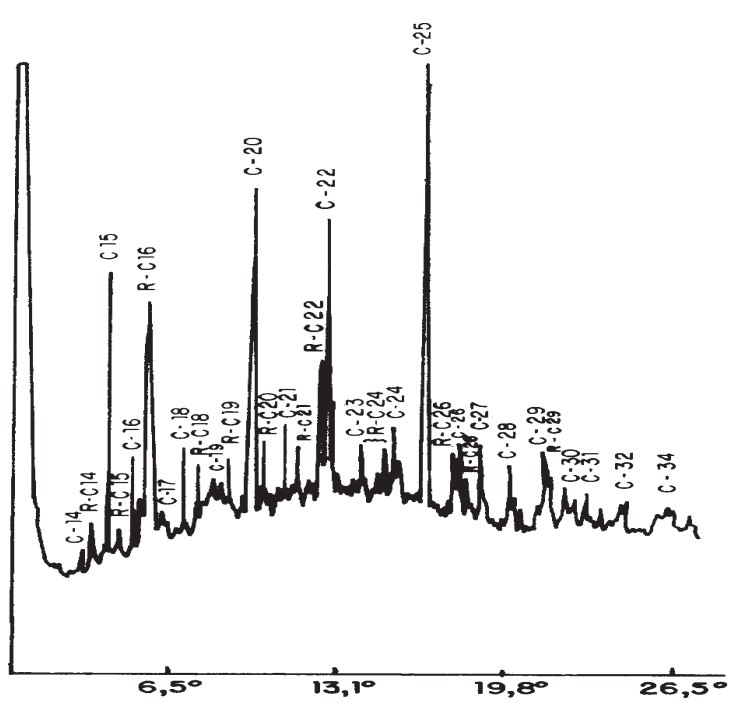

Figura 6. Cromatograma que identifica os ácidos graxos existentes no primeiro extrato da partição água:hexano (2A), obtido pela aplicação do método proposto pelos autores à amostra 1. $\mathbf{R - x}=$ ácido graxo ramificado.

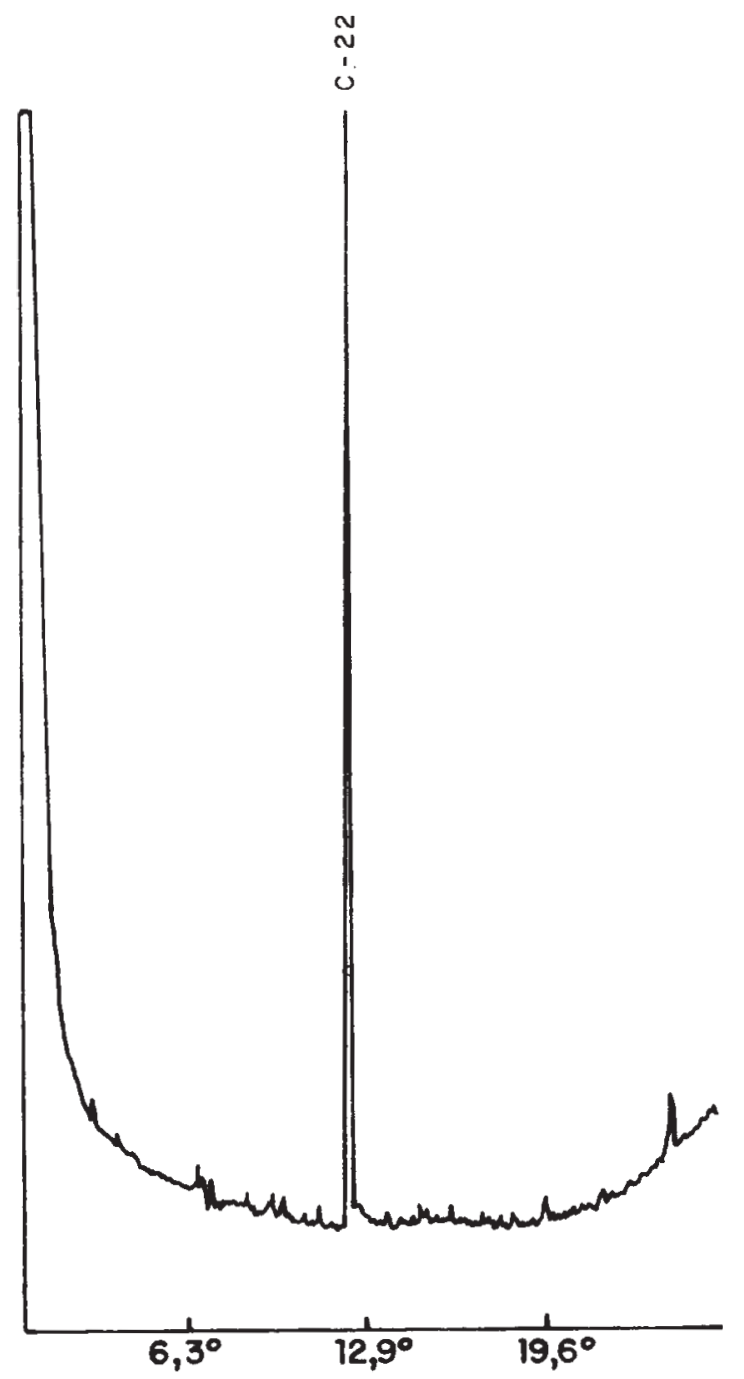

Figura 7. Cromatograma que identifica os ácidos graxos existentes no segundo extrato da partição água:hexano (2B), obtido pela aplicação do método proposto pelos autores à amostra 1.

polaridade do sistema, tendo como conseqüência a formação de clatratos. Comparando os resultados obtidos para a amostra 1 pelo método de Ma'Shum et al. (1988) e por partição no segundo método, verificou-se que os alcanos são a classe química comum obtida pel os dois métodos. Parece, pois, que tal classe venha a ser a responsável pelo caráter hidrofóbico apresentado pela amostra 1. É de se supor, também, que sejam os alcanos de maior peso molecular (acima de C24) que confiram essa hidrofobicidade a essa mesma amostra, visto que esses são os únicos comuns aos dois métodos. Ressalta-se, também, para o caso da amostra 1, que o segundo método discriminou mel hor os compostos orgânicos extraídos do que o método de Ma'Shum et al. (1988) (Quadros 5, 6 e 7). 


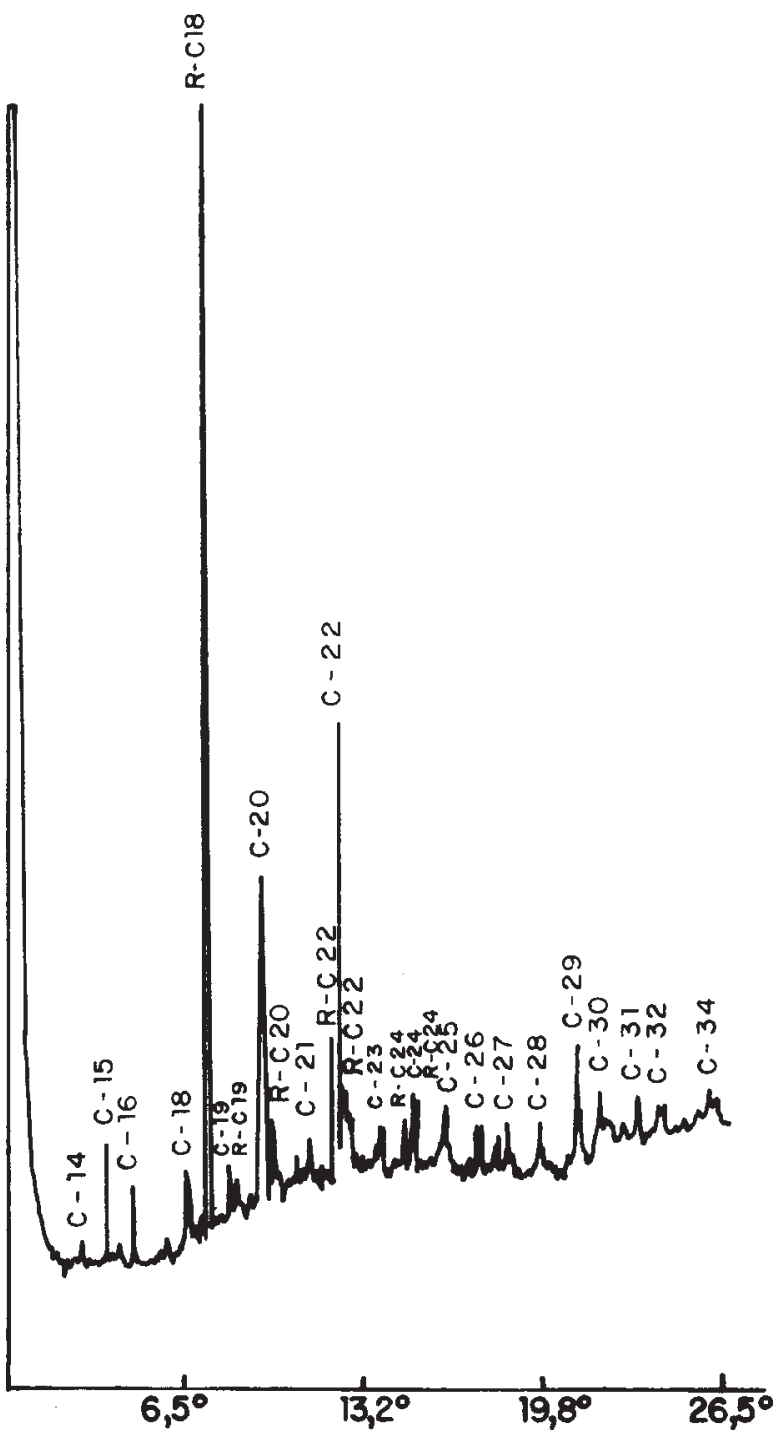

Figura 8. Cromatograma que identifica os ácidos graxos existentes no extrato da partição água:clorofórmio (2C), obti do pela apli cação do método proposto pelos autores à amostra 1. $\mathbf{R}-\mathbf{x}=$ ácido graxo ramificado.

\section{CONCLUSÕES}

1. Os teores de carbono orgânico e os valores de pH em água não se relacionaram com os valores de repelência medidos.

2. Os dois métodos de extração por partição foram igualmente eficientes na retirada das substâncias orgânicas responsáveis pel o fenômeno de repelência à água.

3. O método de extração dos componentes hidrofóbicos por aparato de Sohxlet e partição com água permitiu detalhar melhor a natureza dos diversos componentes al câni cos da amostra de solo.
4. Os resultados evidenciam que as substâncias isoladas têm sua origem na vegetação local, sendo os alcanos de alto peso molecular os responsáveis pelo caráter hidrofóbico das amostras de solo.

\section{LITERATURA CITADA}

ADHIKARI, M. \& CHAKRABARTI, G. Contribution of natural and microbial humic acids to water repellency in soil. J. Ind. Soc. Soil Sci., 24:217-219, 1976.

BOND, R.D. Water repellent soils sands. In: INTERNATIONAL CONGRESS OF SOIL SCIENCE, 9., Adelaide, 1968. Transactions. Amsterdam, International Society of Soil Science, 1968. p.339-347.

BOND, R.D. Factors responsible for water repellence of soils. In: SYMPOSIUM ON WATER REPELLENT SOIL, Riverside, 1969. Proceedings. Riverside: University of California, 1969. p.259-264.

BOND, R.D. Germination and yield of barley when grown in a water-repellent sand. Agron. J ., 64:402-403, 1972.

DeBANO, L.F.; MANN, L.D. \& HAMILTON, D.A. Translocation of hydrophobic substances into soil by burning organic litter. Soil Sci. Soc. Am. Proc., 34:130-133, 1970.

EMPRESA BRASILEIRA DE PESQUISA AGROPECUÁRIA EMBRAPA. Serviço Nacional de Levantamento e Conservação de Solos. Levantamento de reconhecimento dos sol os do estado do Espírito Santo, Rio de J aneiro, 1978. 461p. (EMBRAPA-SNLCS. Bol etim Técnico, 45)

EMPRESA BRASILEIRA DE PESQUISA AGROPECUÁRIA EMBRAPA. Serviço Nacional de Levantamento e Conservação de Solos. REUNIÃO DE CLASSIFICAÇÃO, CORRELAÇÃO E INTERPRETAÇÃO DE APTIDÃO AGRÍ COLA DE SOLOS, 1., Rio de J aneiro, 1978. Anais. Rio deJ aneiro, EMBRAPA-SNLCS/SBCS, 1979a. p.217-218.

EMPRESA BRASILEIRA DE PESQUISA AGROPECUÁRIA EMBRAPA. Serviço Nacional de Levantamento e Conservação de Solos. Manual de métodos de análise de solo. Rio de J aneiro, 1979b. 255p.

GIOVANNINI, G.; LUCCHESI, G. \& CERUELLI, S. Waterrepellent substances and aggregatestability in hydrophobic soil. Soil Sci., 135:110-113, 1983.

KING, P.M. Comparision of methods for measuring severity of water repellence of sandy soils and assessment of some factors that affect its measurement. Aust. J. Soil Res., 19:275-285, 1981.

MA'SHUM, M.; TATE, M.E.; J ONES, G.P. \& OADES, J.M. Extraction and characterization of water-repellent materials from australian soils. J. Soil Sci., 39:99-110, 1988.

McGHIE, D.A. \& POSNER, A.M. Water repellence of a heavy textured Western Australian surface soil. Aust. J. Soil Res., 18:309-323, 1980. 
NAKAYA, N.; YOKOI, H. \& MOTOMURA, S. The method for measuring of water repellency of soil. Soil Sci. Plant Nutr., 23:417-426, 1977.

QUALLS, R.G. \& HAINE, B.L. Geochemistry of dissolved organic nutrients in water percolating through a forest ecosystem. Soil Sci. Soc. Am. J ., 55:1112-1123, 1991.

ROBERTS, F.J . \& CARBON, B.A. Water repellence in sandy soils of South-Western Australia. II. Some chemical characteristics of the hydrophobic skins. Aust. J . Soil Res., 10:35-42, 1972.

SALATINO, A. \& SILVA, J.B. Método para separação de constituintes comuns de ceras vegetais por cromatografia em camada del gada. B. Bot., 10:1-6, 1988.
SCHOOL, D.G. Soil wettability and fire in Arizona chaparral. Soil Sci. Soc. Am. Proc., 39:356-361, 1975.

WALLIS, M.G. \& HORNE, D.J . Soil water repellency. Adv. Soil Sci., 20:91-138, 1992.

WALLIS, M.G.; HORNE, D.J . \& PALMER, A.S. Water repellency in a New Zealand development sequence of Yellow Brown Sands. Aust. J. Soil Res., 31:641-654, 1993.

WALLIS, M.G.; SCOTTER, D.R. \& HORNE, D.J . An evaluation of the intrinsic sorptivity water repellency index on a range of New Zealand soils. Aust. J. Soil Res., 29:353-362, 1991.

WANDER, I.W. An interpretation of the cause of water repellent sandy soils found in citrus groves of central Florida. Science, 110:299-301, 1949. 